\title{
The prognostic value of tumor size in penile cancer: A Surveillance, Epidemiology, and End Results database study
}

\section{Wenwen Zheng}

Qindao University Medical College Affiliated Yantai Yuhuangding Hospital

\section{Zhiyu Zhang}

Qindao University Medical College Affiliated Yantai Yuhuangding Hospital

\section{Wei Jiang}

Qindao University Medical College Affiliated Yantai Yuhuangding Hospital

Jiaojiao Chen

Qindao University Medical College Affiliated Yantai Yuhuangding Hospital

\section{Shengqiang Yu}

Qindao University Medical College Affiliated Yantai Yuhuangding Hospital

Chenyu Guo ( $\nabla$ shgcy@vip.qq.com )

Yantai Yuhuangding Hospital, Qingdao University https://orcid.org/0000-0001-5677-6762

\section{Research}

Keywords: Penile squamous cell carcinoma, SEER, Tumor size, Cancer-specific mortality, Lymph node metastasis

Posted Date: April 2nd, 2021

DOI: https://doi.org/10.21203/rs.3.rs-124807/v2

License: (c) (i) This work is licensed under a Creative Commons Attribution 4.0 International License. Read Full License 


\section{Abstract \\ Background}

The objective of this study was to investigate the prognostic value of tumor size on cancer-specific mortality (CSM) and lymph node metastasis for patients with penile squamous cell carcinoma (PSCC).

\section{Methods}

The patients diagnosed with PSCC between 2004 and 2015 were selected from the Surveillance, Epidemiology, and End Results (SEER) database. Restricted cubic spline functions were calculated to characterize the association between tumor size and the risk of CSM. The competing-risks model was used to evaluate the impact of tumor size on the cumulative incidence of CSM. The logistic regression analysis was performed to examine the association between tumor size and lymph node metastasis.

\section{Results}

Totally, 1365 PSCC patients were analyzed, with $52.3 \%$ having tumors $\leq 30 \mathrm{~mm}$, and $47.7 \%>30 \mathrm{~mm}$. The restricted cubic splines showed that the risks of CSM increased as tumors enlarged. Following adjustment of competing events, the PSCC patients with tumors $>30 \mathrm{~mm}$ were more likely to succumb to CSM in comparison with those with tumors $\leq 30 \mathrm{~mm}$ (hazard ratio $[\mathrm{HR}]=1.57,95 \%$ confidence interval $[\mathrm{Cl}]$ : 1.23-2.01, $P<0.001)$. In subgroup analyses, tumor size $>30 \mathrm{~mm}$ was significantly associated with an increased risk of CSM relative to tumor size $\leq 30 \mathrm{~mm}$ among patients with $\mathrm{T} 1(\mathrm{HR}=1.56,95 \% \mathrm{Cl}$ : 1.03-2.37, $P=0.036)$ and T3 ( $\mathrm{HR}=2.51,95 \% \mathrm{Cl}: 1.41-4.45, P=0.002)$ classifications. On logistic regression analysis, tumors $>30 \mathrm{~mm}$ were significantly associated with lymph node metastasis (odds ratio $[\mathrm{OR}]=1.46,95 \% \mathrm{Cl}: 1.03-2.07, P=0.034)$.

\section{Conclusions}

Larger tumors ( $>30 \mathrm{~mm}$ ) were significantly associated with higher risks of CSM and increased likelihood of lymph node metastasis for PSCC patients, which could be integrated into the development of a staging system for penile cancer.

\section{Introduction}

Penile cancer is an uncommon urogenital malignancy, which accounts for $0.2 \%$ of new cancer cases and $0.1 \%$ of cancer deaths worldwide in 2020 [1]. The annual incidence of penile cancer is about 1.0 per 100000 males in developed countries, including Europe and the US [2, 3]. Whereas, in the developing countries of Africa, Asia, and South America, it reaches to 2.0-4.0 per 100000 males [4]. PSCC, the most frequent histological subtype, composes $95 \%$ of all penile neoplasms [5]. 
For males, the cumulative probability of suffering penile cancer is only $0.09 \%$ from birth to 74 -year-old [1]. Worldwide, an estimated 36068 new penile cancer cases and 13211 penile cancer deaths occurred in 2020 [1]. The American Cancer Society estimates that in the US, the new cases and deaths of penile cancer in 2020 are 2200 and 440, respectively [6]. Due to the rare incidence, the investigations regarding the prognosis of this cancer are relatively less in comparison with other types of cancers. The presence and extent of regional lymph node involvement is the most significant predictor of prognosis among patients with PSCC. Other clinical and pathological variables, including tumor grade [7], tumor thickness [8], histological subtype [9], and lymphovascular invasion [10], are also associated with regional lymph node metastasis and patient survival. Tumor size, an independent prognostic factor in several types of cancer, is frequently utilized to evaluate tumor stage in the American Joint Committee on Cancer (AJCC) staging system [11]. However, the most recent AJCC staging system does not include tumor size as an important criterion for the classification of penile cancer.

To date, limited studies have reported that tumor size is a prognostic predictor of overall survival [12], disease-free survival [13], and cancer recurrence [14] for PSCC. Whereas the association of tumor size with CSM is still unclear. In addition, the association between tumor size and lymph node metastasis has been controversial, and there is a paucity of study focused on this issue. Therefore, the current study was based on the hypothesis that tumor size was significantly associated with CSM as well as lymph node metastasis for PSCC. The population-based SEER database was queried for the eligible patients, and the impact of tumor size on the prognosis of PSCC was evaluated in detail.

\section{Materials And Methods}

\section{Data source}

The SEER database of the National Cancer Institute program (http://www.seer.cancer.gov), covering approximately $28 \%$ of the US population [15], was used to select patients in this study. The cancer-related data were gathered in the SEER database from 1973, which could be freely provided to registered researchers. We used SEER*Stat (version 8.3.6) to extract the data, and our user name to access the database was 11910-Nov2019. All the collected data were de-identified, and hence, our study was exempted from institutional review board approval.

\section{Study population}

The SEER database was queried for all cases who were diagnosed with PSCC between 2004 and 2015. The cases were identified using the primary site codes C60.0-60.9 for penile cancer and morphology codes $8051 / 3,8052 / 3,8070 / 3-8076 / 3,8083 / 3$, and $8560 / 3$ for squamous cell carcinoma. PSCC was the first and only primary diagnosis and confirmed by histological examination. To guarantee the accuracy of tumor size, only patients with cancer-directed surgery performed and tumor size $\leq 100 \mathrm{~mm}$ were included. The exclusion criteria were composed of age $<18$ years at diagnosis, the presence of distant metastasis, and autopsy or death certificate cases. The patients with unknown information about follow-up data, 
tumor size, tumor grade, and tumor stage were also excluded. The flow diagram of patient selection was shown in Figure 1.

\section{Measurements of variables}

The demographic and clinicopathological characteristics of the eligible patients were collected, including age at diagnosis, race (black, white, other), marital status (married, unmarried, unknown), tumor grade (grade $\varangle$, grade $\varangle$, grade $\varangle$, grade $\varangle$ ), tumor size $(\mathrm{mm}), \mathrm{T}$ classification $(\mathrm{T} 1, \mathrm{~T} 2, \mathrm{~T} 3, \mathrm{~T} 4), \mathrm{N}$ classification (N0, N1, N2, N3), chemotherapy (yes, no/unknown), and radiotherapy (yes, no). Tumor size was defined as the largest dimension or diameter of the tumor, which was recorded from the pathology report. The cut-off value of tumor size was set at $30 \mathrm{~mm}$, which was the median value across this variable. Because the selected patients were diagnosed in 2004-2015, we relied on the AJCC Cancer Staging Manual (6th edition, 2004) to evaluate tumor stages. The primary outcome of interest was CSM, defined as the interval from diagnosis of PSCC to death due to PSCC only. CSM was ascertained based on the code "SEER cause-specific death classification" in the SEER database.

\section{Statistical analysis}

Descriptive statistics of demographic and clinicopathological variables were performed for the entire cohort and separately for the subgroups based on tumor size ( $>30 \mathrm{~mm}$ and $\leq 30 \mathrm{~mm}$ ). Continuous variables with normal distribution were summarized as mean \pm standard deviation, and non-normal continuous variables were expressed as median (interquartile range). Categorical variables were described in terms of frequency and percentages. We used the Chi-square test, the Fisher exact test, or the Wilcoxon rank-sum test to evaluate the variables between groups. The reversed Kaplan-Meier method was used to calculate the median follow-up time. Tumor size as both a continuous and categorical variable was analyzed in this study, separately. We produced a histogram to describe the distribution of tumor size. Cumulative incidence curves were built to represent the effects of tumor size on CSM graphically. Gray's test was used to compare the cumulative incidence functions between groups. The restricted cubic splines with four knots at the $0.05,0.35,0.65$, and 0.95 centiles were applied to model the association between tumor size and CSM flexibly. The median of tumor size $(30 \mathrm{~mm})$ across all patients was set to the reference value. The competing-risks regression model (Fine-Gray model) was employed to evaluate the relationship between risk factors and CSM [16]. Additionally, we used multivariable logistic regression models to examine the association between tumor size and lymph node status.

All statistical analyses were performed using R software (version 3.5.3, http://www.r-project.org/). The R package "cmprsk" was used to build cumulative incidence function curves and perform competing risk analysis. The significance level was set at $P<0.05$, two-sided.

\section{Results}

\section{Demographic and clinicopathological characteristics}


Between 2004 and 2015, 1365 PSCC patients who met the inclusion criteria were identified from the SEER database. The demographic and clinicopathological characteristics of the entire cohort and the subgroups stratified by tumor size were presented in Table 1.

Among the 1365 eligible patients, the median age was 65 (55-75) years. There were $1141(83.6 \%)$ white, and $769(56.3 \%)$ of the population were married. PSCC was grade $\nabla$ to $\nabla$ in 414 (30.3\%), $682(50.0 \%), 260$ (19.0\%), and 9 (0.7\%) patients, respectively. When the TNM classification system was used, T classifications were as follows: T1 in 700 (51.3\%), T2 in 400 (29.3\%), T3 in 249 (18.2\%), and T4 in 16 (1.2\%), respectively. N0 stage (80.1\%) predominated in this cohort. The median tumor size was 30 (20-45) mm. Concerning treatment, only 139 of 1365 (10.2\%) received chemotherapy, and 98 of $1365(7.2 \%)$ underwent radiotherapy. The patients in the two subgroups were significantly different in marital status, tumor grade, tumor size, T classification, $\mathrm{N}$ classification, and the receipt of chemotherapy and radiotherapy.

In this study, the median follow-up time was 62 (95\% Cl: 58-69) months. By the end of follow up, 557 patients had died, of which 294 (52.8\%) patients died from PSCC, and 264 (47.2\%) patients died from other causes.

\section{Effect of tumor size on CSM among PSCC patients}

The distribution of tumor sizes was presented in Figure 2. 52.3\% of tumors in the study population were at most $30 \mathrm{~mm}$, and $47.7 \%$ of tumors were larger than $30 \mathrm{~mm}$. Figure 3 exhibited the boxplots of tumor sizes in subgroups based on $\mathrm{T}$ and $\mathrm{N}$ classification, and significant differences could be observed (all $P<0.001)$. The curves for the cumulative incidence functions of CSM stratified by tumor size was displayed in Figure 4. After controlling competitive risk events, a significant difference was observed for the cumulative incidence of CSM between two subgroups $(P<0.001)$.

The effects of tumor size as both a continuous and categorical variable on CSM were separately analyzed. As shown in Figure 5, restricted cubic splines were used to flexible model and visualize the association between tumor size and CSM. The plot depicted an apparent tendency that the risks of CSM increased as tumors enlarged. Multivariable competing-risks regression analyses of CSM were displayed in Table 2. When tumor size was incorporated into the competing-risks regression model as a categorical variable, the estimates indicated that the PSCC patients with tumors $>30 \mathrm{~mm}$ were more likely to succumb to CSM than those with tumors $\leq 30 \mathrm{~mm}$ (HR=1.57, 95\% Cl: 1.23-2.01, $P<0.001)$. Race, Tumor grade, $\mathrm{T}$ classification, and $\mathrm{N}$ classification were independent predictors for CSM. However, no significant association with CSM was found with age at diagnosis, marital status, chemotherapy, and radiotherapy.

\section{Sensitivity analyses for the association between tumor size and CSM}

In the current study, subgroup analyses stratified by $T$ classification were performed to verify the association between tumor size and CSM. As shown in Figure 4, there were statistical differences in cumulative incidence of CSM across the subgroups stratified by $T$ classification (all $P<0.05$ ). The 5 -year 
cumulative incidences of CSM for PSCC patients with tumors $\leq 30 \mathrm{~mm}$ and $>30 \mathrm{~mm}$ in T1 subgroup were $13.2 \%$ and $19.7 \%$, respectively. The corresponding 5 -year cumulative incidences of CSM in T2 subgroup were $24.8 \%$ and $32.0 \%$. For T3 subgroup, 5 -year cumulative incidences of CSM for patients with tumors $\leq 30 \mathrm{~mm}$ and $>30 \mathrm{~mm}$ were $25.5 \%$ and $39.5 \%$, respectively. As Table 3 showed, after adjusting other variables, PSCC patients with tumors $>30 \mathrm{~mm}$ had a 1.56-fold higher chance of CSM than those with tumors $\leq 30 \mathrm{~mm}$ in T1 subgroup $(P=0.036)$. Similarly, for T3 subgroup, the patients with tumors $>30 \mathrm{~mm}$ had worse cancer-specific survival relative to those with tumors $\leq 30 \mathrm{~mm}(\mathrm{HR}=2.51,95 \% \mathrm{Cl}: 1.41-4.45$, $P=0.002$ ). In the multivariable analysis involving T2 classification, tumors $\leq 30 \mathrm{~mm}$ seemed to be a predictor of better cancer-specific survival $(H R=1.49,95 \% \mathrm{Cl}: 0.97-2.27, P=0.067)$, though the statistical significance of the association was of borderline value. Due to the limitation of sample size $(n=16)$, the subgroup analysis on T4 classification was not performed.

\section{Association of tumor size with lymph node status.}

Tumor size as a categorical variable was analyzed by using multivariable logistic regression models. Compared with tumors $\leq 30 \mathrm{~mm}$, the odds ratio (OR) for lymph node metastasis was 1.46 (95\% Cl: $1.03-$ $2.07, P=0.034)$ for tumors $>30 \mathrm{~mm}$. Additionally, age at diagnosis, tumor grade, $T$ classification, chemotherapy, and radiotherapy were all significantly associated with lymph node metastasis. However, no statistical significance was reached with respect to race and marital status. The results of multivariable logistic regression analysis were presented in Table 4.

\section{Discussion}

In the current study, we evaluated the association of tumor size with CSM as well as lymph node metastasis based on the SEER database. The PSCC patients with tumors $>30 \mathrm{~mm}$ were more likely to succumb to CSM than their counterparts with tumors $\leq 30 \mathrm{~mm}$. Additionally, tumor size $>30 \mathrm{~mm}$ was significantly associated with an increased risk of lymph node metastasis.

Due to the rarity of PSCC, only scarce retrospective studies were published to investigate the prognostic value of tumor size. The existing limited literature revealed that tumor size was a prognostic predictor for overall survival, disease-free survival, and cancer recurrence [12-14]. Escande et al identified 201 patients with invasive penile carcinoma to examine the association between brachytherapy and long-term clinical outcomes. Patients with tumors greater than $4 \mathrm{~cm}$ had worse overall survival $(\mathrm{HR}=2.2,95 \% \mathrm{Cl}: 1.1-4.4$, $P=0.028)$ and disease-free survival $(\mathrm{HR}=2.4,95 \% \mathrm{Cl}: 1.2-4.8, P=0.01)$ than those with tumors at most 4 $\mathrm{cm}$ [12]. Mao and colleagues reported that tumors larger than $30 \mathrm{~mm}$ predicted worse overall survival relative to those less than $30 \mathrm{~mm}$ for node-positive penile cancer $(\mathrm{HR}=1.71,95 \% \mathrm{Cl}: 1.28-2.28, P<0.001)$ [13]. However, to date, the association of tumor size and cancer-specific survival has not yet been fully explored. In a recent study, Cox regression models were used to identify the risk factors of cancer-specific survival for PSCC patients with node-positive disease. On multivariable analysis, tumor size $\geq 30 \mathrm{~mm}$ was significantly associated with worse cancer-specific survival [13]. Of note, lymph node-negative patients were not involved in this study, and thus, we did not know the effect of tumor size on CSM for 
lymph node-negative patients. Additionally, the Cox regression model used was not suitable for analysis of competing events, which might overestimate the cumulative incidence of each event and lead to competitive risk bias [17]. The primary interest of our study was CSM. The other causes leading to death, such as cardiovascular disease, suicide, and accident, were regarded as competing events, which could hinder the occurrence of the primary interest. In this case, the competing-risks model was more appropriate to deal with multiple end events. Subgroup analyses were also carried out to verify the robustness of the findings. The patients with tumors $\leq 30 \mathrm{~mm}$ had survival benefits than those with tumors $>30 \mathrm{~mm}$ among T1 and T3 subgroups. However, the statistical significance did not reach in T2 subgroup, which might be attributed to the relatively small sample size that reduced statistical power to detect small effects.

As we knew, the involvement of regional lymph nodes was a valuable pathological factor for predicting the prognosis of PSCC patients $[15,18]$. Therefore, it was consequential to accurately recognize the risk factors associated with regional lymph node metastasis. Previous studies showed that tumor size was associated with an increased likelihood of regional lymph node metastasis for breast cancer [19], thyroid cancer [20], and lung cancer [21]. However, this topic did not reach a consensus on penile cancer. A study from Italy investigated the predictors of lymph node metastasis using 175 PSCC patients. The authors firstly used the Chi-square test to screen the clinical variables. Because of no statistical significance in univariable analysis, tumor size was not incorporated and analyzed in the multivariable analysis [22]. Another study based on the Ontario Cancer Registry was performed to evaluate the predictive variables of lymph node metastasis. The cohort was composed of 380 PSCC patients, of whom 63 patients had pathologically confirmed lymph node metastasis. In univariable analysis, tumor size ( $>3 \mathrm{~cm} v \mathrm{vs} . \leq 3 \mathrm{~cm}$ ) was associated with an increased risk of lymph node metastasis $(P=0.040)$. However, it was not statistically significant at the conventional level (5\%) in multivariable analysis [23]. Commonly, the reliable estimation of predictor effects needed at least 100 events. The requirement of sample size was at least 10 events per variable (EPV), and preferably 20 [24]. In the two studies, the number of events was only 71 and 63 , and the values of EPV were respectively 15 and 9, less than 20 . The relatively small sample size and low values of EPV might decrease the statistical power and the reliability of these results to some extent. In our study, 271 of 1365 patients were confirmed with lymph node-positive disease, and the value of EPV in multivariable analysis exceeded 30. Therefore, our study had sufficient sample size and statistical power to obtain stable and reliable estimations of predictor effects. Our study showed tumors $>30 \mathrm{~mm}$ was significantly associated with an increased likelihood of lymph node metastasis compared to tumors $\leq 30 \mathrm{~mm}(\mathrm{OR}=1.46,95 \% \mathrm{Cl}$ : $1.03-2.07, P=0.034)$. Consistent with our findings, Chalya and colleagues identified 236 penile cancer patients from a medical center in Tanzania, of whom 154 patients had lymph node metastasis at diagnosis. The multivariable logistic regression analysis showed that tumor size was an independent predictor for lymph node metastasis ( $\geq 20 \mathrm{~mm}$ vs. $<20 \mathrm{~mm}$, $\mathrm{OR}=2.9,95 \% \mathrm{Cl}: 1.1-6.4, P=0.011)$ [14]. Kearns and collaborators reported that increasing tumor size was significantly associated with lymph node metastasis after adjusting $T$ classification, tumor grade, and lymphovascular invasion ( $\geq 40 \mathrm{~mm}$ vs. $<15 \mathrm{~mm}, \mathrm{OR}=2.9,95 \% \mathrm{Cl}: 1.31-6.41, P=0.009$ ) as well [7]. 
The current study had its own advantages. The population-based SEER database was employed in this study, providing us a relatively large sample size, which was beneficial for the investigations on cancers with low incidence. In addition, this study systemically investigated the prognostic value of tumor size for PSCC by using multiple statistical methods, including restricted cubic splines, competing-risks models, and logistic regression models. These reliable results exhibited the potential prognostic value of tumor size in the development of a staging system for penile cancer. However, some limitations should be noted. First of all, the selection bias was inevitable due to the retrospective nature of this study. Second, although we had adjusted for many known patient factors, the estimation would be more accurate if more valuable covariables which were not recorded in the SEER database could be incorporated. Third, since the eligible patients were diagnosis in 2004-2015, the relatively short follow-up might influence the estimation of cumulative incidence of CSM.

\section{Conclusions}

To our knowledge, the prognostic value of tumor size was firstly investigated for PSCC in this study. Compared to tumors $\leq 30 \mathrm{~mm}$, tumors $>30 \mathrm{~mm}$ were significantly associated with worse cancer-specific survival and increased likelihood of lymph node metastasis. These findings could help clinicians and investigators to perform patient counseling, design clinical trials, and improve cancer staging systems. Further investigations are needed to confirm the prognostic value of tumor size for penile cancer.

\section{Abbreviations}

CSM: cancer-specific mortality; PSCC: penile squamous cell carcinoma; SEER: Surveillance, Epidemiology, and End Results; AJCC: American Joint Committee on Cancer; HR: hazard ratio; 95\% Cl: 95\% confidence interval; OR: odds ratio.

\section{Declarations}

\section{Ethics approval and consent to participate}

The study was conducted in accordance with the Declaration of Helsinki (as revised in 2013). We were permitted to access the SEER database after submitting SEER Research Data Agreement forms. All the collected data were de-identified, and hence, our study was exempted from institutional review board approval. Additionally, due to the retrospective nature of this study, the requirement for informed consent was waived.

\section{Consent for publication}

Not applicable.

\section{Availability of data and materials.}


The datasets generated and/or analyzed during the current study are available in the SEER repository (http://www.seer.cancer.gov).

\section{Competing interests}

The authors declare that they have no conflict of interest.

\section{Funding}

Not applicable.

\section{Authors' contributions}

Wenwen Zheng and Zhiyu Zhang participated in study design. Wei Jiang and Jiaojiao Chen were responsible for data collection and analysis. Wenwen Zheng was involved in drafting the manuscript. Shengqiang Yu and Chenyu Guo made appropriate revisions. All authors have read and approved the final manuscript.

\section{Acknowledgments}

The authors acknowledge the SEER program of NIH for providing high-quality data to researchers. The authors are also grateful for the support provided by their colleagues.

\section{References}

1. Sung H, Ferlay J, Siegel RL, et al. Global cancer statistics 2020: GLOBOCAN estimates of incidence and mortality worldwide for 36 cancers in 185 countries [published online ahead of print, 2021 Feb 4]. CA Cancer J Clin. 2021. 10.3322/caac.21660. doi:10.3322/caac. 21660.

2. Backes DM, Kurman RJ, Pimenta JM, et al. Systematic review of human papillomavirus prevalence in invasive penile cancer. Cancer Causes Control. 2009;20(4):449-57.

3. Chaux A, Netto GJ, Rodriguez IM, et al. Epidemiologic profile, sexual history, pathologic features, and human papillomavirus status of 103 patients with penile carcinoma. World J Urol. 2013;31(4):8617.

4. Chaux A, Cubilla AL. Advances in the pathology of penile carcinomas. Hum Pathol. 2012;43(6):77189.

5. Thuret $\mathrm{R}$, Sun $\mathrm{M}$, Abdollah F, et al. Tumor grade improves the prognostic ability of American Joint Committee on Cancer stage in patients with penile carcinoma. J Urol. 2011;185(2):501-7.

6. [Internet] American Cancer Society. Key Statistics for Penile Cancer. https://www.cancer.org/cancer/penilecancer/about/key-statistics.html. Accessed July 15, 2020.

7. Kearns JT, Winters BD, Holt SK, et al. Pathologic nodal involvement in patients with penile cancer with cavernosal versus spongiosal involvement. Clin Genitourin Cancer. 2019;17(1):e156-61. 
8. Cubilla AL. The role of pathologic prognostic factors in squamous cell carcinoma of the penis. World J Urol. 2009;27(2):169-77.

9. Sanchez DF, Soares F, Alvarado-Cabrero I, et al. Pathological factors, behavior, and histological prognostic risk groups in subtypes of penile squamous cell carcinomas (SCC). Semin Diagn Pathol. 2015;32(3):222-31.

10. Li K, Sun J, Wei X, et al. Prognostic value of lymphovascular invasion in patients with squamous cell carcinoma of the penis following surgery. BMC Cancer. 2019;19(1):476.

11. Amin MB, Edge SB, Greene FL et al, editors. AJCC Cancer Staging Manual. 8th ed. New York: Springer; 2017.

12. Escande A, Haie-Meder $C$, Mazeron R, et al. Brachytherapy for conservative treatment of invasive penile carcinoma: prognostic factors and long-term analysis of outcome. Int $\mathrm{J}$ Radiat Oncol Biol Phys. 2017;99(3):563-70.

13. Mao W, Huang $X$, Kong $M$, et al. More lymph node dissection improves survival in patients with newly diagnosed lymph node-positive penile cancer. Int Urol Nephrol. 2019;51(4):641-54.

14. Chalya PL, Rambau PF, Masalu N, et al. Ten-year surgical experiences with penile cancer at a tertiary care hospital in northwestern Tanzania: a retrospective study of 236 patients. World J Surg Oncol. 2015;13:71.

15. Zheng W, Li K, Zhu W, et al. Nomogram prediction of overall survival based on log odds of positive lymph nodes for patients with penile squamous cell carcinoma. Cancer Medicine. 2020;9(15):542535.

16. Fine JP, Gray RJ. A Proportional hazards model for the subdistribution of a competing risk. J Am Stat Assoc. 1999;94(446):496-509.

17. Yang J, Pan Z, He Y, et al. Competing-risks model for predicting the prognosis of penile cancer based on the SEER database. Cancer Med. 2019;8(18):7881-9.

18. Ficarra V, Akduman B, Bouchot O, et al. Prognostic factors in penile cancer. Urology. 2010;76(2 Suppl 1):66-73.

19. Sopik V, Narod SA. The relationship between tumour size, nodal status and distant metastases: on the origins of breast cancer. Breast Cancer Res Treat. 2018;170(3):647-56.

20. Nguyen XV, Roy Choudhury K, Tessler FN, et al. Effect of tumor size on risk of metastatic disease and survival for thyroid cancer: implications for biopsy guidelines. Thyroid. 2018;28(3):295-300.

21. Yu X, Li Y, Shi C, et al. Risk factors of lymph node metastasis in patients with non-small cell lung cancer $\leq 2 \mathrm{~cm}$ in size: A monocentric population-based analysis. Thorac Cancer. 2018;9(1):3-9.

22. Ficarra V, Zattoni F, Cunico SC, et al. Lymphatic and vascular embolizations are independent predictive variables of inguinal lymph node involvement in patients with squamous cell carcinoma of the penis: Gruppo Uro-Oncologico del Nord Est (Northeast Uro-Oncological Group) Penile Cancer data base data. Cancer. 2005;103(12):2507-16. 
23. Qu XM, Siemens DR, Louie AV, et al. Validation of predictors for lymph node status in penile cancer: Results from a population-based cohort. Can Urol Assoc J. 2018;12(4):119-25.

24. Steyerberg E. Clinical prediction models: A practical approach to development, validation, and updating. 2nd ed. Germany: Springer International Publishing; 2019.

\section{Tables}

Table 1. Demographics and clinicopathological characteristics of PSCC patients

\begin{tabular}{|c|c|c|c|c|}
\hline \multirow[t]{2}{*}{ Variables } & \multirow{2}{*}{$\begin{array}{l}\text { All patients } \\
(\mathrm{n}=1365)\end{array}$} & \multicolumn{2}{|c|}{ Tumor size } & \multirow[t]{2}{*}{$\bar{P}$} \\
\hline & & $\leq 30 \mathrm{~mm}(\mathrm{n}=714)$ & $>30 \mathrm{~mm}(\mathrm{n}=651)$ & \\
\hline Age at diagnosis, year & $65(55-75)$ & $65(55-75)$ & $65(55-75)$ & 0.974 \\
\hline \multicolumn{5}{|l|}{ Race } \\
\hline White & $1141(83.6 \%)$ & 597 (83.6\%) & $544(83.6 \%)$ & \multirow[t]{4}{*}{0.932} \\
\hline Black & $132(9.7 \%)$ & $67(9.4 \%)$ & $65(10.0 \%)$ & \\
\hline Other & $84(6.2 \%)$ & $45(6.3 \%)$ & $39(6.0 \%)$ & \\
\hline Unknown & $8(0.6 \%)$ & $5(0.7 \%)$ & $3(0.5 \%)$ & \\
\hline \multicolumn{5}{|l|}{ Marital status } \\
\hline Married & 769 (56.3\%) & $422(59.1 \%)$ & 347 (53.3\%) & \multirow[t]{3}{*}{0.042} \\
\hline Unmarried & $519(38.0 \%)$ & 249 (34.9\%) & $270(41.5 \%)$ & \\
\hline Unknown & 77 (5.6\%) & $43(6.0 \%)$ & $34(5.2 \%)$ & \\
\hline \multicolumn{5}{|l|}{ Tumor grade } \\
\hline Grade I & $414(30.3 \%)$ & $243(34.0 \%)$ & $171(26.3 \%)$ & \multirow[t]{4}{*}{0.017} \\
\hline Grade II & $682(50.0 \%)$ & $340(47.6 \%)$ & $342(52.5 \%)$ & \\
\hline Grade III & $260(19.0 \%)$ & $126(17.6 \%)$ & $134(20.6 \%)$ & \\
\hline Grade IV & $9(0.7 \%)$ & $5(0.7 \%)$ & $4(0.6 \%)$ & \\
\hline Tumor size, mm & $30(20-45)$ & $20(14-25)$ & $45(38-57)$ & $<0.001$ \\
\hline \multicolumn{5}{|l|}{$\mathrm{T}$ classification } \\
\hline $\mathrm{T} 1$ & $700(51.3 \%)$ & $465(65.1 \%)$ & 235 (36.1\%) & \multirow[t]{4}{*}{$<0.001$} \\
\hline $\mathrm{T} 2$ & $400(29.3 \%)$ & $168(23.5 \%)$ & $232(35.6 \%)$ & \\
\hline T3 & $249(18.2 \%)$ & $80(11.2 \%)$ & $169(26.0 \%)$ & \\
\hline $\mathrm{T} 4$ & $16(1.2 \%)$ & $1(0.1 \%)$ & $15(2.3 \%)$ & \\
\hline \multicolumn{5}{|l|}{$\mathbf{N}$ classification } \\
\hline N0 & $1094(80.1 \%)$ & $613(85.9 \%)$ & 481 (73.9\%) & \multirow[t]{4}{*}{$<0.001$} \\
\hline N1 & 102 (7.5\%) & $44(6.2 \%)$ & $58(8.9 \%)$ & \\
\hline N2 & 105 (7.7\%) & $39(5.5 \%)$ & $66(10.1 \%)$ & \\
\hline N3 & $64(4.7 \%)$ & $18(2.5 \%)$ & $46(7.1 \%)$ & \\
\hline \multicolumn{5}{|l|}{ Chemotherapy } \\
\hline Yes & $139(10.2 \%)$ & 55 (7.7\%) & 84 (12.9\%) & \multirow[t]{2}{*}{0.002} \\
\hline No/Unknown & 1226 (89.8\%) & 659 (92.3\%) & 567 (87.1\%) & \\
\hline \multicolumn{5}{|l|}{ Radiotherapy } \\
\hline Yes & 98 (7.2\%) & 40 (5.6\%) & 58 (8.9\%) & \multirow[t]{2}{*}{0.018} \\
\hline No & 1267 (92.8\%) & 674 (94.4\%) & $593(91.1 \%)$ & \\
\hline
\end{tabular}


Table 2. Multivariable competing-risks regression analyses of CSM

\begin{tabular}{|c|c|c|}
\hline Variable $(n=1365)$ & HR (95\% CI) & $P$ \\
\hline Age at diagnosis & $1.01(1.00-1.02)$ & 0.064 \\
\hline \multicolumn{3}{|l|}{ Race } \\
\hline White & Ref. & \\
\hline Black & $1.12(0.79-1.58)$ & 0.540 \\
\hline Other & $0.49(0.26-0.91)$ & 0.024 \\
\hline Unknown & - & - \\
\hline \multicolumn{3}{|l|}{ Marital status } \\
\hline Married & Ref. & \\
\hline Unmarried & $1.02(0.80-1.31)$ & 0.870 \\
\hline Unknown & $0.88(0.49-1.57)$ & 0.660 \\
\hline \multicolumn{3}{|l|}{ Tumor grade } \\
\hline Grade I & Ref. & \\
\hline Grade II & $2.06(1.45-2.94)$ & $<0.001$ \\
\hline Grade III & $2.44(1.62-3.69)$ & $<0.001$ \\
\hline Grade IV & $4.35(1.89-9.98)$ & $<0.001$ \\
\hline \multicolumn{3}{|l|}{$\mathrm{T}$ classification } \\
\hline $\mathrm{T} 1$ & Ref. & \\
\hline $\mathrm{T} 2$ & $1.16(0.86-1.56)$ & 0.330 \\
\hline T3 & $1.26(0.90-1.76)$ & 0.190 \\
\hline $\mathrm{T} 4$ & $2.19(1.15-4.19)$ & 0.017 \\
\hline \multicolumn{3}{|l|}{$\mathrm{N}$ classification } \\
\hline N0 & Ref. & \\
\hline N1 & $2.37(1.65-3.40)$ & $<0.001$ \\
\hline $\mathrm{N} 2$ & $2.93(1.99-4.32)$ & $<0.001$ \\
\hline N3 & $4.76(2.93-7.74)$ & $<0.001$ \\
\hline \multicolumn{3}{|l|}{ Chemotherapy } \\
\hline Yes & Ref. & \\
\hline No/Unknown & $0.92(0.63-1.36)$ & 0.690 \\
\hline \multicolumn{3}{|l|}{ Radiotherapy } \\
\hline Yes & Ref. & \\
\hline No & $1.14(0.74-1.77)$ & 0.550 \\
\hline \multicolumn{3}{|l|}{ Tumor size } \\
\hline$\leq 30 \mathrm{~mm}$ & Ref. & \\
\hline$>30 \mathrm{~mm}$ & $1.57(1.23-2.01)$ & $<0.001$ \\
\hline
\end{tabular}

Abbreviations: HR, hazard ratio; 95\% CI, 95\% confidence interval. 
Table 3. Multivariable analyses for the impact of tumor size on CSM stratified by T classification.

\begin{tabular}{cccccc}
\hline Subgroups & Variables & $\begin{array}{c}\text { No. of } \\
\text { patients }\end{array}$ & $\begin{array}{c}\text { 5-year cumulative incidence of } \\
\text { CSM }\end{array}$ & HR (95\%CI) & $P$ \\
\hline T1 & $\leq 30 \mathrm{~mm}$ & 465 & $13.2 \%$ & Ref. & \\
classification & $>30 \mathrm{~mm}$ & 235 & $19.7 \%$ & $1.56(1.03-$ & 0.036 \\
& & & & $2.37)$ & \\
T2 & $\leq 30 \mathrm{~mm}$ & 168 & $24.8 \%$ & Ref. & \\
\cline { 2 - 6 } classification & $>30 \mathrm{~mm}$ & 232 & $32.0 \%$ & $1.49(0.97-$ & 0.067 \\
& & & & $2.27)$ & \\
T3 & $\leq 30 \mathrm{~mm}$ & 80 & $25.5 \%$ & Ref. & \\
classification & $>30 \mathrm{~mm}$ & 169 & $39.5 \%$ & $2.51(1.41-$ & 0.002 \\
& & & & $4.45)$ & \\
\hline
\end{tabular}

Abbreviations: HR, hazard ratio; 95\% CI, 95\% confidence interval; CSM, cancer-specific mortality.

All models were adjusted for age at diagnosis, race, marital status, tumor grade, $\mathrm{N}$ classification, chemotherapy, and radiotherapy.

Table 4. Multivariable logistic regression analysis for the association of tumor size with lymph node metastasis. 


\begin{tabular}{|c|c|c|}
\hline Variable $(n=1365)$ & OR (95\% CI) & $P$ \\
\hline Age at diagnosis & $0.98(0.97-1.00)$ & 0.006 \\
\hline \multicolumn{3}{|l|}{ Race } \\
\hline White & Ref. & \\
\hline Black & $0.95(0.53-1.66)$ & 0.863 \\
\hline Other & $1.62(0.81-3.10)$ & 0.157 \\
\hline Unknown & - & - \\
\hline \multicolumn{3}{|l|}{ Marital status } \\
\hline Married & Ref. & \\
\hline Unmarried & $1.20(0.84-1.71)$ & 0.313 \\
\hline Unknown & $1.41(0.67-2.80)$ & 0.348 \\
\hline \multicolumn{3}{|l|}{ Tumor grade } \\
\hline Grade I & Ref. & \\
\hline Grade II & $2.68(1.66-4.48)$ & $<0.001$ \\
\hline Grade III & $5.43(3.18-9.50)$ & $<0.001$ \\
\hline Grade IV & $3.05(0.32-17.37)$ & 0.259 \\
\hline \multicolumn{3}{|l|}{ T classification } \\
\hline $\mathrm{T} 1$ & Ref. & \\
\hline $\mathrm{T} 2$ & $3.28(2.18-5.00)$ & $<0.001$ \\
\hline T3 & $3.80(2.42-6.00)$ & $<0.001$ \\
\hline $\mathrm{T} 4$ & $4.28(1.07-15.72)$ & 0.032 \\
\hline \multicolumn{3}{|l|}{ Chemotherapy } \\
\hline Yes & Ref. & \\
\hline No/Unknown & $0.06(0.04-0.10)$ & $<0.001$ \\
\hline \multicolumn{3}{|l|}{ Radiotherapy } \\
\hline Yes & Ref. & \\
\hline No & $0.18(0.10-0.32)$ & $<0.001$ \\
\hline \multicolumn{3}{|l|}{ Tumor size } \\
\hline$\leq 30 \mathrm{~mm}$ & Ref. & \\
\hline$>30 \mathrm{~mm}$ & $1.46(1.03-2.07)$ & 0.034 \\
\hline
\end{tabular}

Abbreviations: OR, odds ratio; 95\% CI, 95\% confidence interval;

Figures 
2743 Patients with penile squamous cell carcinoma from the SEER database (2004-2015)

\section{Excluded}

427 With unknown tumor grade

371 With unknown $\mathrm{T}$ or $\mathrm{N}$ classification

97 With unknown follow-up information

82 With cancer-directed surgery unperformed

344 With tumor size larger than $100 \mathrm{~mm}$ or unknown

57 With M1 classification or unknow M classification

\section{Figure 1}

Diagrammatic flow of patient selection. 


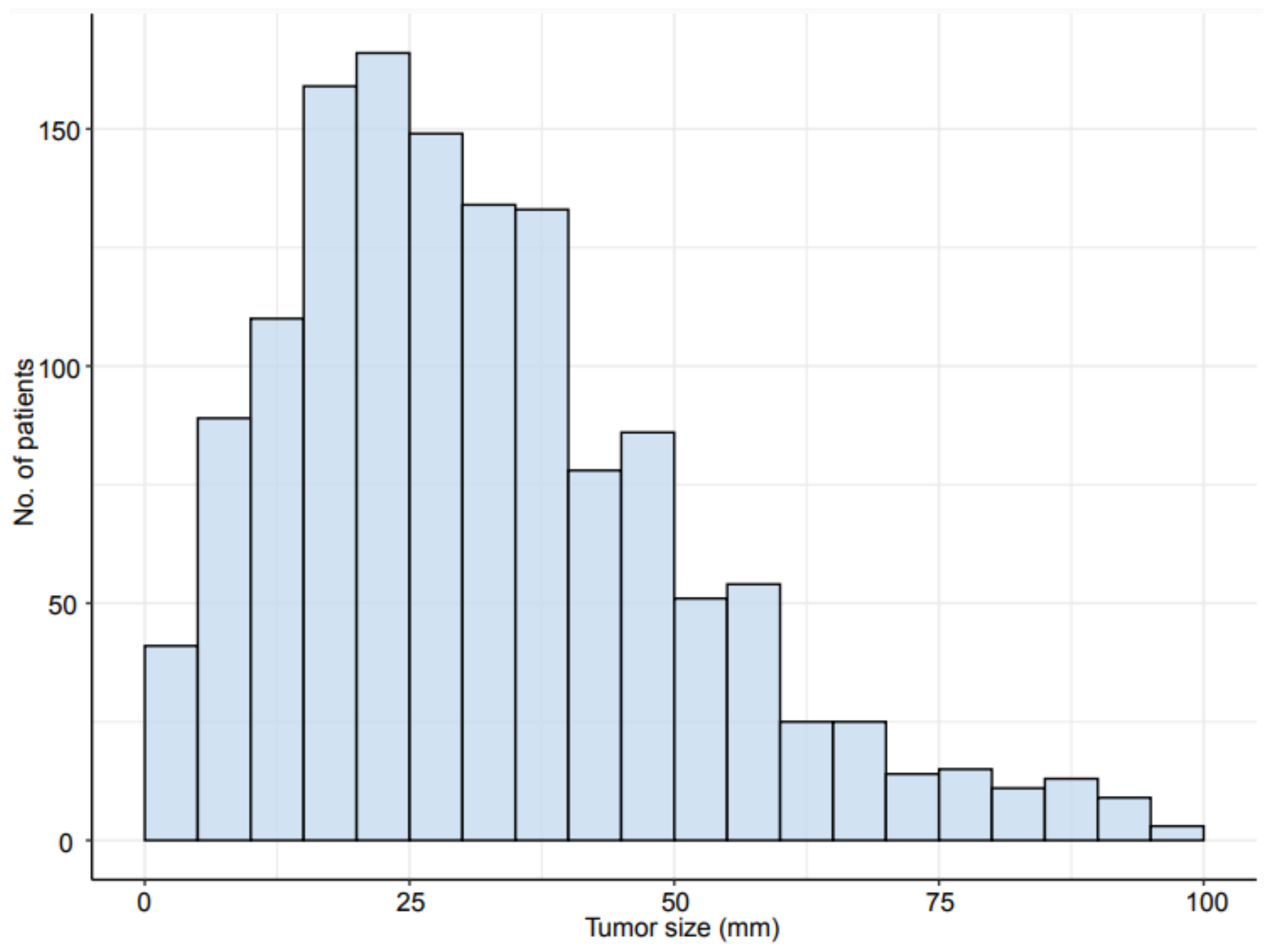

Figure 2

Distribution of tumor sizes of the study population. $52.3 \%$ of tumors were at most $30 \mathrm{~mm}$, and $47.7 \%$ of tumors were larger than $30 \mathrm{~mm}$. 


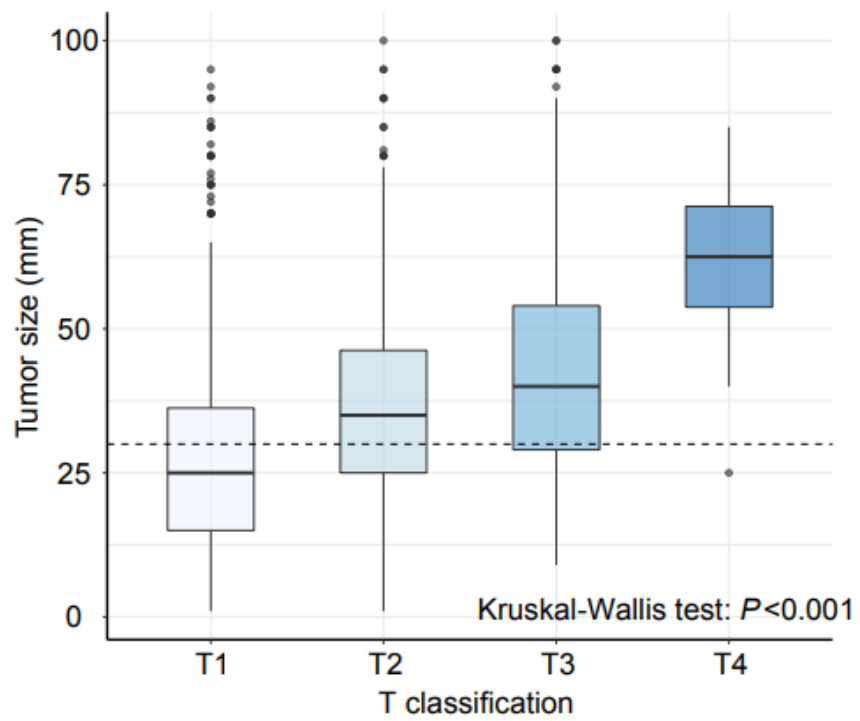

(A)

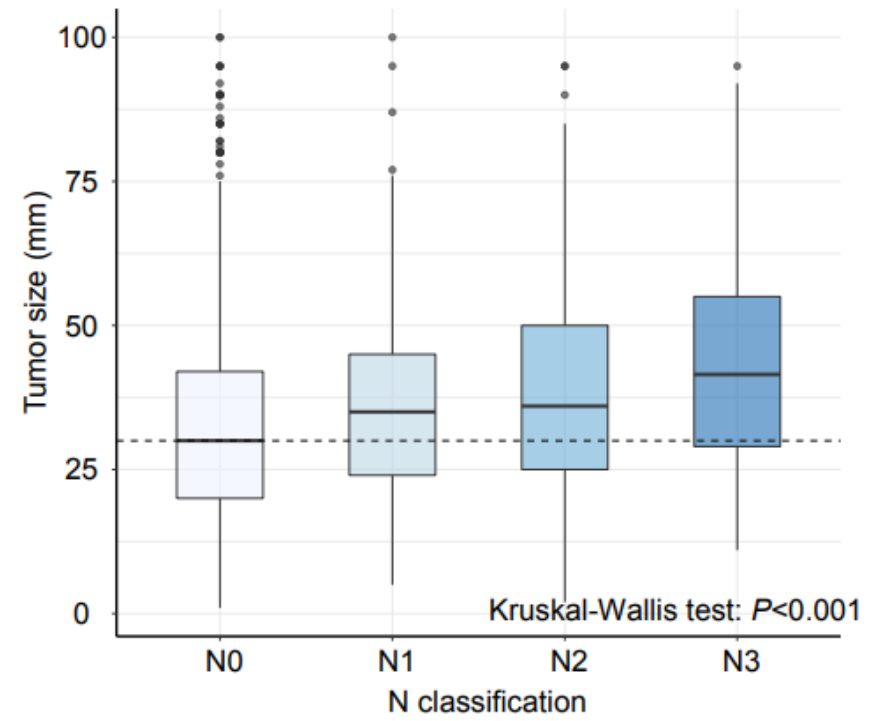

(B)

\section{Figure 3}

Distribution of tumor sizes stratified by $\mathrm{T}(\mathrm{A})$ and N (B) classifications. The dash lines in the boxplots represented the median of tumor size across the study population $(30 \mathrm{~mm})$. 
All Patients

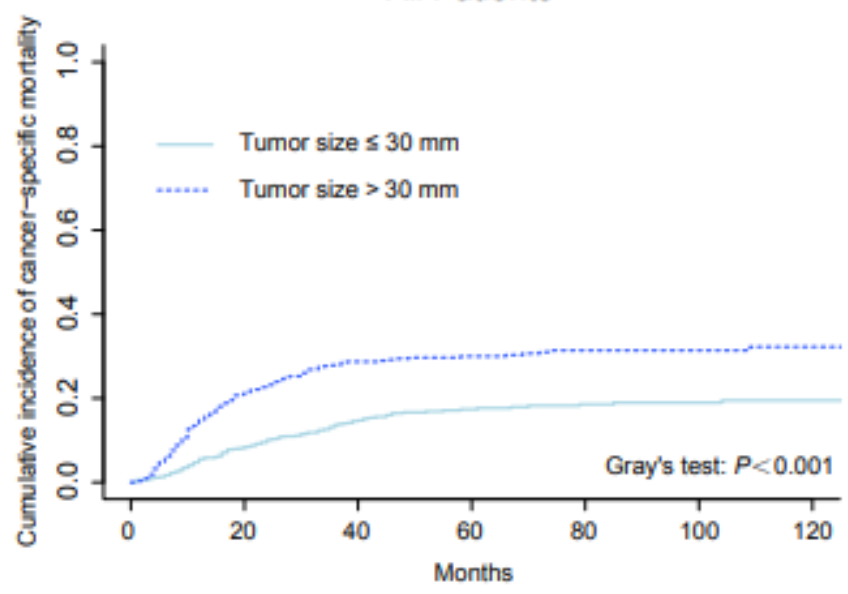

(A)

T2

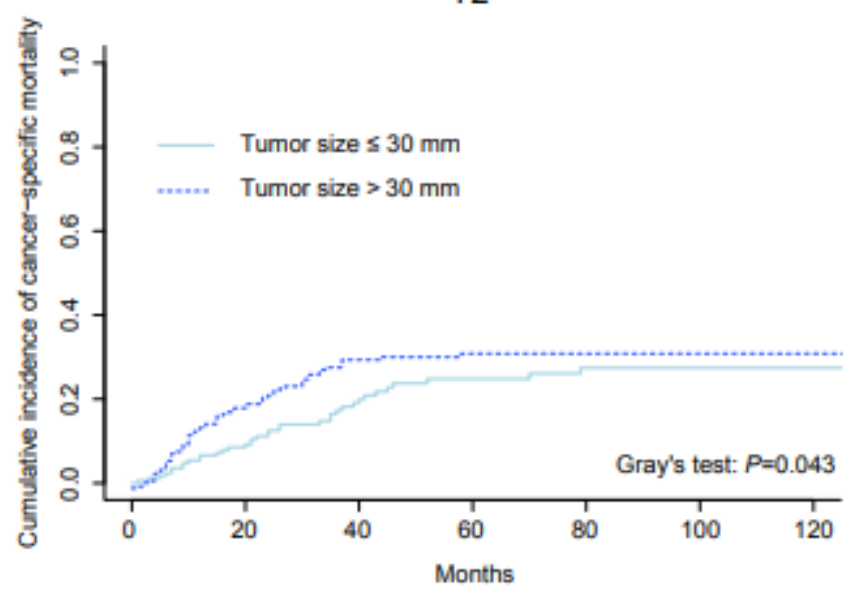

(C)
T1

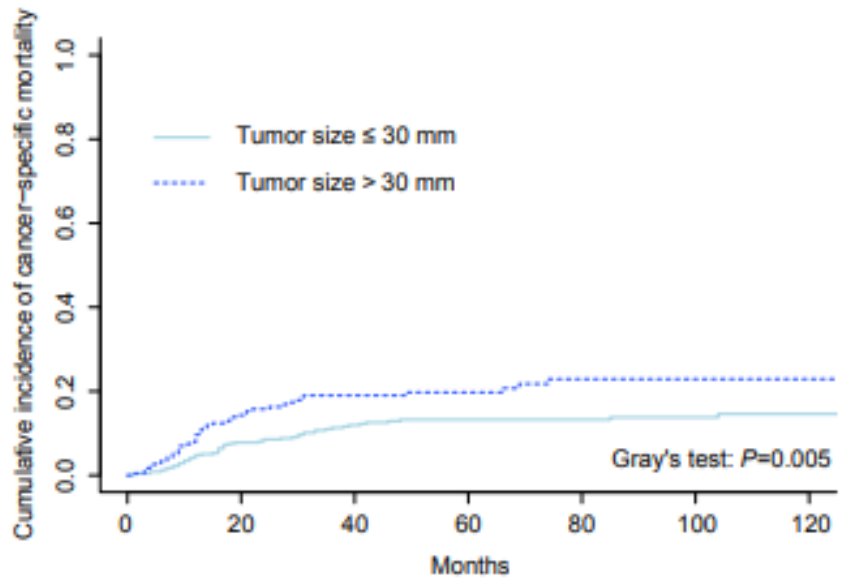

(B)

T3

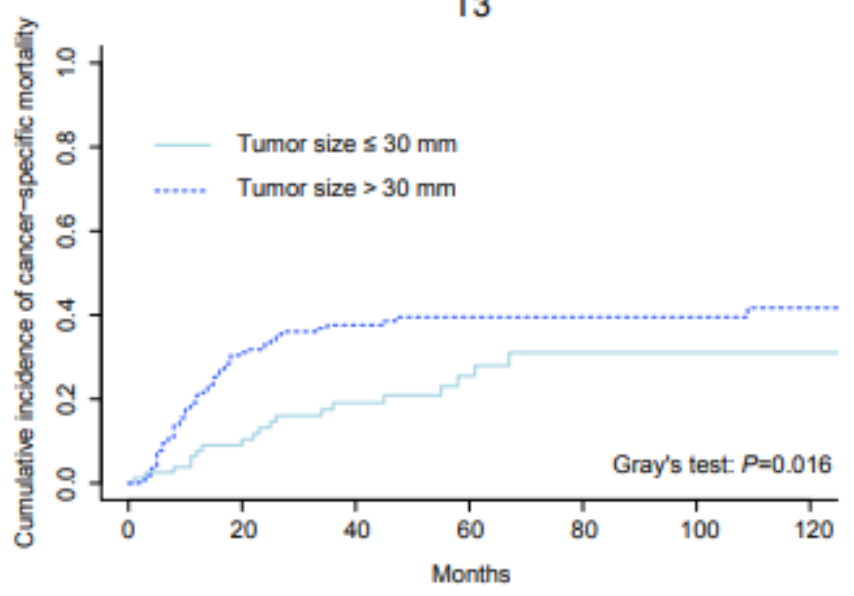

(D)

\section{Figure 4}

The cumulative incidences of CSM stratified by tumor size for the entire cohort (A), T1 subgroup (B), T2 subgroup (C), and T3 subgroup (D). 


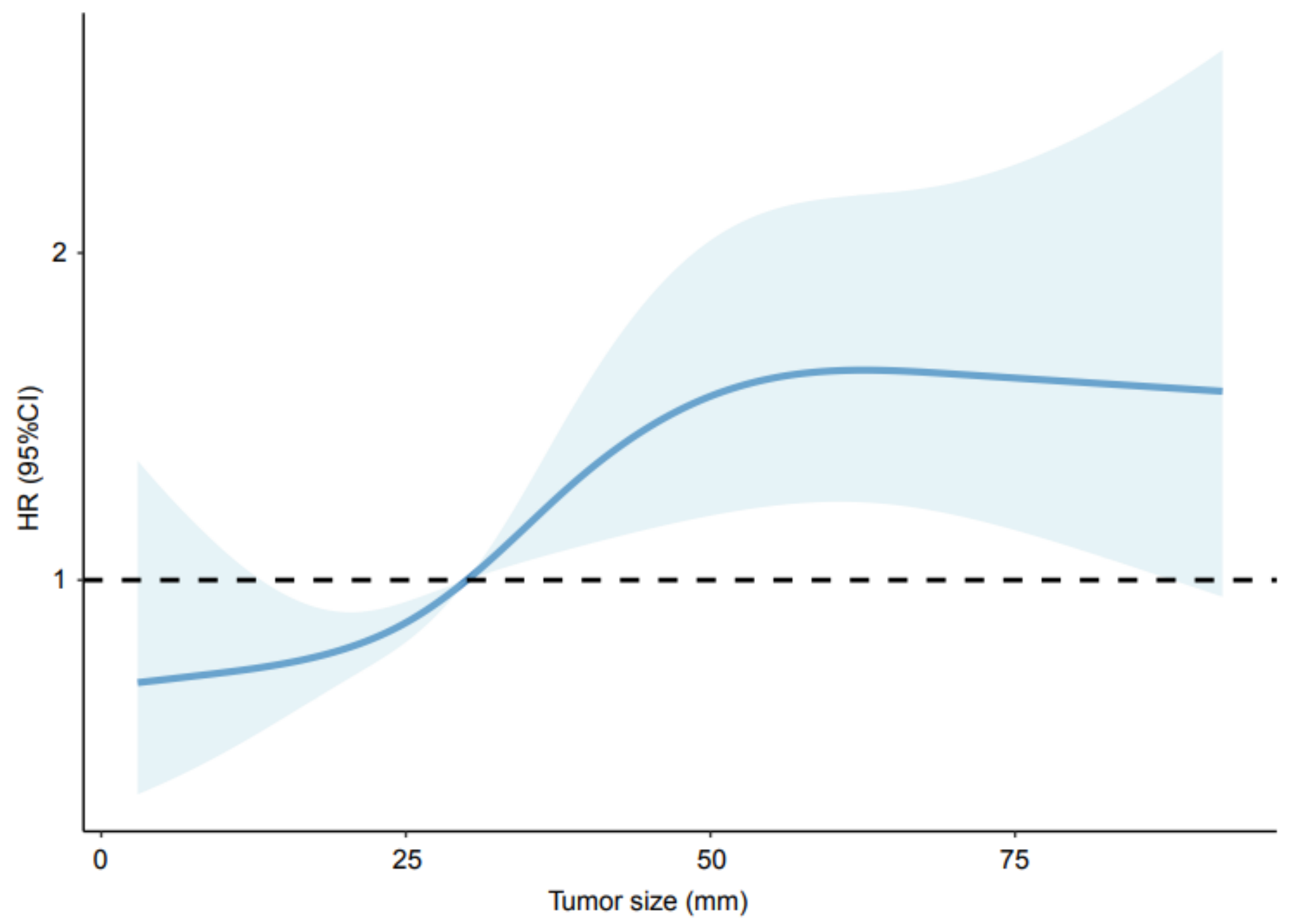

Figure 5

Association between tumor size and CSM for the entire cohort. The solid line represented HRs, and shaded area represented $95 \% \mathrm{Cl}$. The reference point was set at $30 \mathrm{~mm}$ for tumor size $(\mathrm{HR}=1)$. The model was adjusted for the covariables listed in Table 2. 